\title{
TELECOMMUNICATIONS IN GREAT BRITAIN
}

$I^{\mathrm{T}}$ T has become almost traditional that, when an engineer-in-chief of the Post Office assumes office as president of the Institution of Electrical Engineers, he should give in his inaugural address a broad general review of the state of the telecommunications art in Great Britain.

The address of Sir Archibald Gill, delivered on October 5, dealt in the main with the telephone service. In his opening remarks Sir Archibald paid tribute to the work of Sir Thomas Purves in the development of the telephone service, and he referred at several stages in his address to the far-reaching decisions made by Sir Thomas in the early 1920's in regard to the form of automatic switching to be adopted by the Post Office and to the appraisal of these decisions in the light of the developments in the twenty-five years since they were taken. "Some of the newer systems," said Sir Archibald, "have particular advantages such as greater availability on their switches or speedier operation. None, however, has the simplicity and the universality of the stepby-step system, which allows the same components and the same circuits to be used in the smallest and the largest exchanges. Thus it is probable that if a similar decision had to be made to-day, the choice would be the same as it was twenty-five years ago. ... Since 1945 teams of experts from this country have visited all the countries of the world where telephone development has been taking place. Much useful information has been acquired as a result of these visits, but nothing we have seen has suggested that the step-by-step system is obsolete or even obsolescent. . . . In fact, it is becoming obvious that there would be no gain now, and it is extremely doubtful whether there would be any gain in the future, in changing the present basic system for any other electro-mechanical system, and that the present system will meet all our needs satisfactorily until such time as something entirely novel appears, as, for example, an electronic system."

The possibility of developing an electronic switching system is, said Sir Archibald, "the subject of much interesting speculation by telephone engineers". A first step was taken towards the introduction of electronic switching equipment by the development of an electronic director which would perform the functions of the electro-mechanical director at present carrying out the routing of calls in large telephoneexchange areas. A two-digit electronic director has already been designed and tested, and field trials will be carried out under service conditions so that a direct comparison can be made of the performance of the electronic director with that of its electromechanical counterpart.

Referring to the progress of the change-over from manual to automatic switching, Sir Archibald stated that to-day 3.6 million stations are served by automatic exchanges, while about one and a half million are still served by manual exchanges.

The capital which has been invested in the localdistribution cables and lines connecting telephone subscribers to the central offices in Great Britain represents some forty per cent of the total capital value of the telephone system, and there is in con. sequence a strong incentive to effect economies in this item of telephone plant. One method of reducing the cost of local-distribution cable which has been practised extensively in other countries, particularly the United States, is that of connecting more than one subscriber to one pair of conductors. During recent years when it became necessary to give the utmost service with limited plant, the practice of shared service or party-line working was instituted in Great Britain, and some two hundred and thirty thousand subscribers are at present utilizing this service.

The lead-covered, paper-insulated cables at present used for local distribution are not free from disadvantageous features, among which is their vulnerability to mechanical damage and to chemical and electrolytic corrosion. Experiments are in progress on the use of the plastic polythene as an alternative insulant and sheath material for distribution cables.

In the matter of signalling by dial impulses in the telephone network, the development was initiated during the Second World War of dialling over the trunk network connecting the main centres of population. In the system now being used, signals are sent by currents of two frequencies, 600 and $750 \mathrm{c} / \mathrm{s} .$, transmitted over the speech circuit. "The present objective in the mechanisation of the inland trunk network is that a controlling operator situated at any trunk centre shall be able to complete a call to any subscriber connected to an automatic exchange anywhere in the country without the assistance of another operator. This will result in a considerable increase of tandem dialling over the trunk network, involving in some cases up to six links (four trunks and two local junctions) in tandem connected via the banks of switches."

A study group of the International Telephone Advisory Committee is engaged in examining the more complex problem of long-distance dialling over international circuits. It has been agreed among the administrations concerned to subject two schemes to practical trial on circuits inter-connecting London, Amsterdam, Brussels, Paris and Zurich. With the mechanization, not only of local-line switching but also of the trunk network, the familiar multiple switchboard with its rows of answering and calling jacks is now disappearing from trunk exchanges and is being replaced by a cordless type of switchboard in which cord circuits are replaced by key-controlled connecting circuits.

It is probably in the sphere of long-distance transmission that the most rapid advances have been made in recent years, the two notable developments mainly responsible being the negative-feedback amplifier and the co-axial cable. The reduction of intermodulation obtained by the application of negative feedback has rendered it "possible to contemplate putting large numbers of such amplifiers in tandem over long routes and to use them to amplify simultaneously $\mathbf{a}_{\mathbf{b}}$ large number of telephone conversations spread over a wide frequency band extending upwards to a million or more cycles per second".

"The use of co-axial cable solved the problem of cross-talk, or transfer of energy by the coupling between different pairs of conductors, at these high frequencies; for, while it is practicable to produce cables containing twisted pairs in which the crosstalk is not excessive at frequencies up to $100 \mathrm{kc} . / \mathrm{s}$., it becomes increasingly difficult to do so at higher frequencies. On the other hand, the co-axial cable 
behaves conversely ; it has excessive cross-talk below about $50 \mathrm{kc} . / \mathrm{s}$. but improves rapidly at higher frequencies." The co-axial cable is essential for the transmission of television signals. For purposes of multi-channel telephony on co-axial cable systems, "the agreed international standard system is now 960 channels per pair in the frequency range 60 $4,028 \mathrm{kc} . / \mathrm{s}$., using $\frac{3}{8}$-in. co-axial cable with amplifiers at 10 -kilometre intervals. . . For television transmission over these $\frac{3}{8}$-in. co-axial cables the Post Office is planning to use a vestigial-sideband system in which the video signal modulates a carrier of $1 \mathrm{Mc} . / \mathrm{s}$. : the upper sideband extending to $4 \mathrm{Mc} . / \mathrm{s}$. and a vestigial lower sideband extending down to $0.5 \mathrm{Mc} . / \mathrm{s}$. will be transmitted. This frequency transposition is necessary because the television signals extend to well below $50 \mathrm{c} . / \mathrm{s}$. and it is impracticable to send such frequencies over the co-axial cable because of cross-talk."

A four-tube co-axial cable was laid between London and Birmingham in 1936, and it was intended to use one pair of tubes for telephony and the other pair for television. The growth of traffic, however, brought both pairs into use for telephony and it became necessary after the War to plan an additional cable. "At the time when the design of the cable was being considered the Television Advisory Committee under the chairmanship of Lord Hankey had recommended in its report published in 1945 that the television service should be resumed using the pre-war 405-line system and that it should be extended to Birmingham and to other provincial centres, but that development of a higher definition system should be actively pursued. The report also visualized that the two systems would have to exist side by side for some time. The Post Office was thus faced with the possibility of having to provide, in the near future, transmission facilities for a system requiring a band-width of 10-20 Mc. $/ \mathrm{s}$. As the new cable would occupy the sole remaining duct in the route, it was decided that at least one pair of conductors should be capable of carrying the highest definition television likely to be developed either in black-and-white or in colour." The new cable was therefore designed with two tubes of special construction having outer and inner conductors of $0.975 \mathrm{in}$. and $0.250 \mathrm{in}$. effective diameters. This cable has been manufactured and installed, and has been found to come well within the specification limits for impedance, uniformity and attenuation throughout the frequency range of $30 \mathrm{Mc}$. $/ \mathrm{s}$. At $30 \mathrm{Mc} . / \mathrm{s}$. the attenuation of the special tubes is less than $9 \mathrm{db}$. per mile. The design of amplifiers and compensating networks for television links calls for work of the highest precision, "as the object is to attain a transmission standard which will ensure that the picture is not noticeably degraded after transmission over a distance, ultimately, of at least 500 miles". For the cable television link between Birmingham and Manchester "the gain of each amplifier at the maximum frequency (now $4 \cdot 34 \mathrm{Mc}$./s.) is $52 \mathrm{db}$. and the system must be accurately compensated for phase-shift as well as gain/frequency response".

Sir Archibald prefaced his remarks on submarine cables with a reminder that this year marks the centenary of the laying of the first submarine cable across the Straits of Dover. The most important advance in recent years in relation to submarine cables has been the introduction of carrier working, as on land cables. "This has meant the development of improved dielectrics having lower losses at higher frequencies, and the adoption of the co-axial or concentric type of cable instead of the multi-core type ... . the most important step in this direction has been the substitution of polythene for natural insulants." The other important advance has been the development of submerged repeaters to permit the use of higher frequencies. The first submerged amplifier in a Post Office submarine cable was laid in a co-axial cable between Anglesey and the Isle of Man. In 1946 a single amplifior was connected into the cable, 197 nautical miles long, from Lowestoft to Borkum, which had been laid to give direct telephone communication with Western Germany. The trafficcarrying capacity of this cable was thereby increased from one telephone and six telegraph circuits to five telephone circuits any one of which may be used to provide eighteen telegraph channels.

Further development has been directed towards. designing a standard system for co-axial submarine: cables of the lengths used on the Continental routes. This system, which provides sixty circuits per cable, was first used on the Aldeburgh-Domburg cables, the traffic capacity of which has been increased by a factor of five by the insertion, in each, of four submerged repeaters. The operational success of the submerged repeater is naturally dependent on the consistent longevity of its component parts, notably its thermionic valves. Considerable progress has been made in the production of small batches of valves with a predicted life in excess of five years.

In regard to the overseas radio-telephone services, difficulties are imposed by the limitation of the frequency spectrum available for these services. The most effective way of making the best use of this limited spectrum is by developing single-sideband multi-channel working, and considerable progress has been made with the conversion of circuits from double-sideband to single-sideband operation. "At the present time 38 circuits are being operated, of which 28 (including one of the two ship services) are obtained by single- or multi-channel operation on 12 single sideband senders. . . The growth of traffic has been steady. On the eight London-New York circuits, the number of calls per week averages about 1,600 and is increasing at the rate of about 200 calls per week per annum."

Television programmes are transmitted, on carrier frequencies of the order of $900 \mathrm{Mc}$./s., from Alexandra Palace in London to the new television broadcasting station at Sutton Coldfield, Birmingham, by means of a chain of radio links which was brought into use in 1949. The extension of this service will be by co-axial cable to Manchester. From Manchester to Kirk o' Shotts near Edinburgh another chain of radio links will be employed. Two carrier frequencies in the region of $4,000 \mathrm{Mc} . / \mathrm{s} .(7.5 \mathrm{~cm}$.) will be used, and the transmission will be by frequency modulation with a deviation of about $7 \mathrm{Mc}$. $\mathrm{s}$.

Two experimental demonstrations were given during the address. The first was of an equipment developed for the amplitude-and phase-equalization of the short cable links often used between the pick-up point and the control centre in television outside broadcasts. Equalization is effected by trial-and-error adjustment of the equalizer to restore the 'rectangular' form of $20-1$ sec. pulses, of 0.1 , sec. build-up time, transmitted over the line. The second demonstration was the transmission of a television test pattern from the Alexandra Palace studio over the double length of the new London-Birmingham co-axial cable to the lecture theatre of the Institution of Electrical Engineers.
JAMES Greig 